\title{
Insulin Administration Acutely Decreases Vaspin Serum Concentrations in Humans
}

\author{
Peter Kovacs ${ }^{a} \quad$ Konstanze Miehle ${ }^{a}$ Benjamin Sandner ${ }^{a}$ \\ Michael Stumvolla, b Matthias Blüher ${ }^{a}$

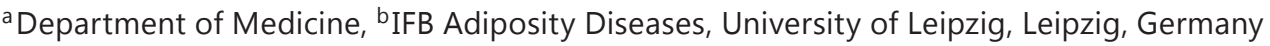

\section{Key Words}

Vaspin · Insulin tolerance test · Insulin

\begin{abstract}
It has been hypothesized that insulin might mediate meal-related diurnal variation in vaspin serum concentrations. We therefore investigated whether insulin affects serum vaspin levels in humans. Vaspin serum concentrations were determined by ELISA in 10 healthy individuals, who underwent an insulin tolerance test (ITT) for the evaluation of pituitary ACTH and growth hormone reserve. The ITTs were started 08:00 am after an overnight fast with a bolus i.v. insulin dose of $0.15 \mathrm{IU} / \mathrm{kg}$ body weight (Actrapid ${ }^{\top \mathrm{M}}$ ). Blood samples were taken at $-15,0,15,30$, 60, 90, and 120 min after insulin administration. 15 min after insulin administration, vaspin serum concentrations decreased by $19 \pm 6 \%$, continued to decrease by $42 \pm 12 \%$ at 60 min and returned to $88 \pm 7 \%$ of initial values 120 min after insulin administration. Our data suggest that meal-related changes in serum vaspin concentrations might be mediated by insulin.
\end{abstract}

\section{Introduction}

Vaspin is a novel adipokine with insulin-sensitizing and glucose-lowering effects in animal models of obesity and type 2 diabetes $[1,2]$. We have recently shown that vaspin is expressed in the stomach, and both peripheral and central vaspin administration decrease food intake in obese $d b / d b$ and lean C57BL/6 mice [2]. Jeong et al. [3] studied 24-hour profiles of circulating vaspin concentrations in relation to meal ingestion in healthy adults. They examined 10 male subjects who were provided with meals on a fixed schedule. On a separate day, 4 subjects fasted and then were provided with an unexpected meal. Regardless whether 
Kovacs et al.: Insulin Administration Acutely Decreases Vaspin Serum Concentrations in Humans

Fig. 1. Vaspin serum concentration during an insulin-induced hypoglycemia test. The test was performed at 08:00 am after an overnight fast for 12-14 $\mathrm{h}$ with a bolus i.v. insulin dose of $0.15 \mathrm{IU} / \mathrm{kg}$ body weight. *p $<0.05 ;{ }^{* *} \mathrm{p}<0.01$ compared to baseline ( $0 \mathrm{~min})$.

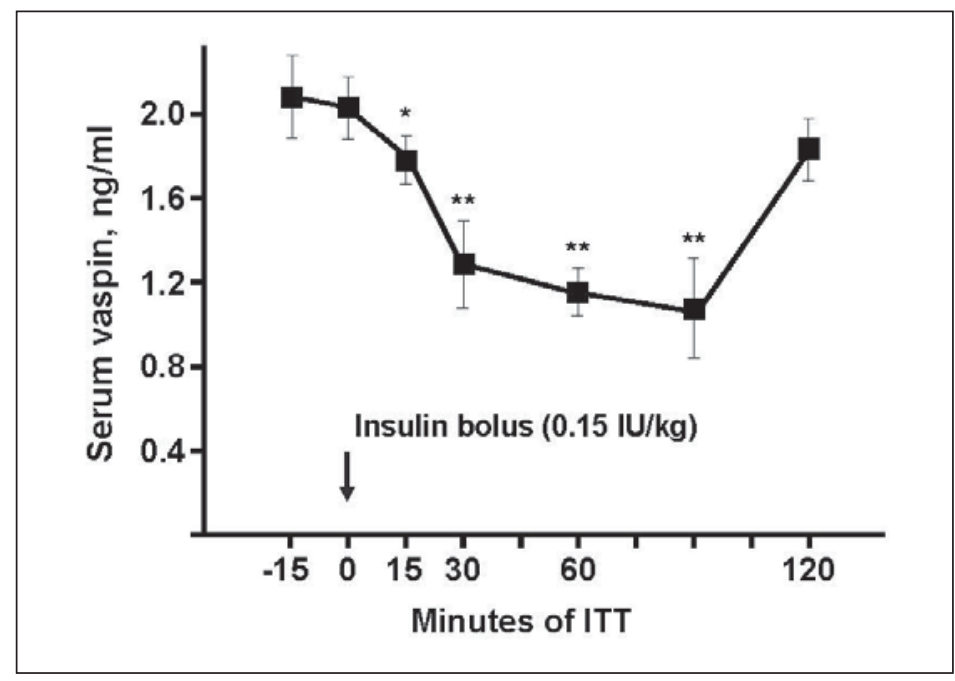

the meal was provided with or without previous notice, serum vaspin levels had a mealrelated diurnal variation, with a preprandial rise and a postprandial fall. The diurnal pattern of serum vaspin concentrations was reciprocal to that of insulin and glucose, suggesting that the postprandial decrease in serum vaspin levels may be caused by energy intake itself or in response to increased insulin and/or glucose plasma concentrations [3]. We therefore aimed to dissect the effects of nutrient intake and increasing glucose concentrations from the effects of insulin on circulating vaspin levels. We tested the hypothesis that insulin administration causes decreased vaspin serum concentrations during a diagnostic insulin-induced hypoglycemia test (insulin tolerance test; ITT).

\section{Methods}

We screened 32 consecutive individuals who were referred to our endocrinology outpatient clinic to examine activity of the hypothalamo-pituitary-adrenal axis by an ITT. 10 healthy individuals ( 5 women and 5 men) with a mean BMI of $23.7 \pm 1.1 \mathrm{~kg} / \mathrm{m}^{2}$ without concomitant medication were included into the study, since they met the criteria that adrenocorticotropic hormone (ACTH), cortisol, and growth hormone serum concentrations are normal during the ITT. At baseline, study participants had mean fasting plasma glucose concentration of $5.28 \pm 0.33 \mathrm{mmol} / \mathrm{l}$. The mean fasting plasma insulin concentration was $18 \pm 11 \mathrm{pmol} / \mathrm{l}$.

ITT was performed at 08:00 am after an overnight fast for 12-14 h with a bolus i.v. insulin dose of 0.15 IU/kg body weight (Actrapid ${ }^{\mathrm{TM}}$, NovoNordisk, Bagsvaerd, Denmark). Blood samples were taken at -15, 0, 15, $30,60,90$, and 120 min after insulin administration for the measurement of plasma glucose, ACTH, serum cortisol, and vaspin. Serum vaspin concentrations were determined as previously described [4]. The study was approved by the Ethics Committee of the University of Leipzig. All subjects gave written informed consent before taking part in the study.

\section{Results}

As early as $15 \mathrm{~min}$ after insulin administration and independently of significant hypoglycemia, vaspin serum concentrations significantly decreased by $19 \pm 6 \%$, continued to decrease by $42 \pm 12 \%$ at $60 \mathrm{~min}$, and returned to $88 \pm 7 \%$ of initial values 120 min after insulin administration (fig. 1). 
Kovacs et al.: Insulin Administration Acutely Decreases Vaspin Serum Concentrations in Humans

\section{Conclusion}

Our data suggest that previously observed meal-related decreases in serum vaspin concentrations [3] are mediated by insulin independently of nutrient intake and glucose concentrations.

\section{Author Contributions}

P.K. designed experiments and wrote manuscript, K.M. performed experiments, B.S. performed experiments, M.S. edited the manuscript, M.B. analyzed data, designed experiments, and wrote the manuscript.

\section{Acknowledgements}

This work was supported by grants from the German Research Council (DFG - Deutsche Forschungsgemeinschaft) KFO 152 'Atherobesity' (project BL 833/1-1 to M.B.) and KO 3880. P.K. is funded by Boehringer Ingelheim Foundation.

\section{Disclosure Statement}

All authors declare that there is no conflict of interest associated with this manuscript.

\section{References}

1 Hida K, Wada J, Eguchi J, Zhang H, Baba M, Seida A, et al: Visceral adipose tissue-derived serine protease inhibitor: a unique insulin-sensitizing adipocytokine in obesity. Proc Natl Acad Sci U S A 2005;102:1061010605.

2 Klöting N, Kovacs P, Kern M, Heiker JT, Fasshauer M, Schön MR, et al: Central vaspin administration acutely reduces food intake and has sustained blood glucose-lowering effects. Diabetologia 2011;54:1819-1823.

3 Jeong E, Youn B-S, Kim DW, Kim EH, Park JW, Namkoong C, et al: Circadian rhythm of serum vaspin in healthy male volunteers: relation to meals. J Clin Endocrinol Metab 2010;95:1869-1875.

4 Youn BS, Klöting N, Kratzsch J, Lee N, Park JW, Song ES, et al: Serum vaspin concentrations in human obesity and type 2 diabetes. Diabetes 2008;57:372-377. 